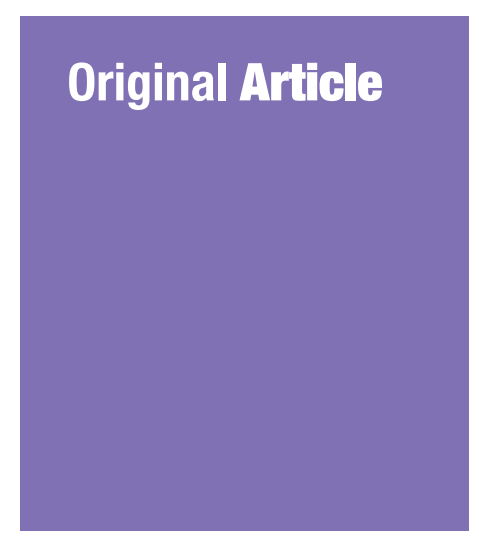

Submitted: 17 Jan 2017 Accepted: 20 Feb 2017 Online: 30 Jun 2017

\section{Prediction of Histological Grade and Completeness of Resection of Intracranial Meningiomas: Role of Peritumoural Brain Edema}

\author{
Kamalanathan Palaniandy 1,2,3,4,5, Mohammad Saffari Mohammad \\ HASPANI $^{1}$, Norzaini Rose Mohd ZaIN ${ }^{6}$
}

Department of Neurosurgery, Hospital Kuala Lumpur, Jalan Pahang, 50586 Kuala Lumpur, Malaysia

2 Department of Surgery, Faculty of Medicine, Universiti Kebangsaan Malaysia, Hospital Canselor Tuanku Muhriz, Pusat Perubatan UKM, 56000 Cheras, Kuala Lumpur, Malaysia

3 Center for Neuroscience Services and Research, Universiti Sains Malaysia, Jalan Sultanah Zainab 2, 16150 Kubang Kerian, Kelantan, Malaysia

4 Department of Neurosciences, Hospital Universiti Sains Malaysia, Jalan Hospital USM, 16150 Kubang Kerian, Kelantan, Malaysia

5 Department of Neurosciences, Universiti Sains Malaysia, Jalan Sultanah Zainab 2, 16150 Kubang Kerian, Kelantan, Malaysia

6 Department of Radiology, Hospital Kuala Lumpur, Jalan Pahang, 50586 Kuala Lumpur, Malaysia

To cite this article: Palaniandy K, Mohammad Haspani MS, Mohd Zain NR. Prediction of histological grade and completeness of resection of intracranial meningiomas: role of peritumoural brain Edema. Malays $J$ Med Sci. 2017;24(3):33-43. https://doi.org/10.21315/mjms2017.24.3.5

To link to this article: https://doi.org/10.21315/mjms2017.24.3.5

\title{
Abstract
}

Background: Meningioma is the commonest primary intracranial tumour in adults. Excision is curative for low grade meningioma, whereas high-grade meningioma requires adjuvant therapy following surgery. Several studies have examined the association between peritumoural brain Edema - a common feature in meningioma - and histological grading with mixed results. The present study attempted to elucidate this association and if peritumoural brain Edema affects the intra-operative judgement of surgeons on the completeness of resection.

Methods: An observational study was conducted among those who underwent surgery for meningioma. Eighteen subjects were recruited each for low- and high-grades, respectively. Magnetic resonance imaging (MRI) prior to surgery was employed for interpreting the Edema index and MRI after surgery was used to determine residual tumour.

Results: Median age was 50 years, male to female ratio was 1:3.5, 69.4\% had peritumoural brain Edema and $75 \%$ had reported gross resection. Among the reported gross total resection cases, $40.7 \%$ had residual tumour. Analysis showed statistically significant association between peritumoural brain Edema $(P=0.027)$ and tumour volume $(P=0.001)$ with high-grade meningioma, however multivariate analysis did not present any association. No association was noted between judgement of tumour resection by surgeons and peritumoural brain Edema.

Conclusion: Odds ratio for peritumoural brain Edema remained high and the tumour volume exhibited marginal $P$-value marginal significance for prediction of high grade meningioma. These two factors may still contribute to the tumour grade and should be included in further studies on the prognosis of meningioma.

Key words: meningioma, Edema, resection 


\section{Introduction}

Meningiomas make up $33.8 \%-34.4 \%$ of the primary intracranial tumours observed in adults and are even more common than glial tumours, which comprise $31.1 \%$ of all primary intracranial tumours (1-2). Advancing age increases the risk of a diagnosis of meningioma, with the highest risk occurring between 60 and 70 years of age (2). Meningioma is assumed to arise from the arachnoid, particularly from the outer arachnoid layer and arachnoid villi, which are called the arachnoid cap cells and are diverse in their distribution throughout the central nervous system (3).

Meningiomas are distinguishable into three histological grades. Grade 1 meningioma occurs in almost $80 \%$ of cases, has a low proliferative potential, and is often cured through surgical resection. Grade 2 meningioma may infiltrate locally despite its low proliferative potential and also carries a probability of recurrence. Grade 3 meningioma generally reveals histological evidence of malignancy, including nuclear atypia and brisk mitotic activity (4).

Meningioma patients usually present with seizures, symptoms of raised intracranial pressure, and focal neurological deficits that are associated with the location of the tumour. These symptoms are exacerbated by peritumoural Edema and are occasionally visible when peritumoural Edema is present or increases (5-6).

Surgery alone is usually sufficient to treat grade 1 meningioma; despite complete excision, grade 2 meningioma has an eight-fold increased risk of recurrence (3). Grade 3 meningioma is considerably more aggressive, with an average survival period of two years or less (7). Despite some prior controversies, adjuvant radiotherapy continues to be recommended to treat grades 2 and 3 due to the locally invasive nature of the disease. Nevertheless, recent data regarding adjuvant therapy have shown promising results comparable with a second surgery for incomplete excision and recurrence (8-9).

The amount of peritumoural Edema is associated with the degree of blood-brain barrier breakdown; thus, if the tumour grade (malignancy) is higher, then the extent of the blood-brain barrier breach is greater. Therefore, tumours with a higher grade tend to produce more Edema (10).

Several studies have investigated the association between peritumoural brain Edema and the histopathological categorisation of the meningioma. While a few researchers have reported a significant connection (11-12), others have observed no such association (13-15). Thus, the connection between the histopathological grading of the meningioma and the presence of peritumoural brain Edema remains obscure.

Surgical intervention in intracranial meningioma patients aims for complete resection, which produces an improved longterm recurrence rate $(6,16)$. Attempts have been made to determine whether peritumoural Edema results from local infiltration and if the presence of vascular endothelial growth factor influences the totality of the resection of the intracranial meningioma (10,17-18). This study examined the relationship between the presence of peritumoural Edema and the histological outcome of the meningioma. We also attempted to determine whether peritumoural Edema in any way affected the surgeons' judgement regarding the completeness of the resection.

\section{Materials and Methods}

This cross-sectional observational study was conducted over a 5 -year period on patients who had undergone a first-time tumour excision at Hospital Kuala Lumpur of a histologically confirmed meningioma. Institutional ethical approval was obtained from the Medical Research and Ethics Committee of the Ministry of Health in Malaysia.

Over a 5-year period, 168 cases of histologically confirmed intracranial meningioma were identified. Less than half of these cases (78 patients) were included in this study largely due to missing data or a delay in performing a follow-up magnetic resonance imaging (MRI) scan post surgery.

\section{Peritumoural brain Edema}

Brain Edema is defined as an expansion of the brain volume due to increased water and sodium content (20). This condition is identified on MRI as a hyper-intense image on T2-weighted scans and as a hypo-intense one on T1-weighted scans (21).

In the current study, the tumour volume and Edema were measured using pre-operative contrast-enhanced MRI films. The sagittal and coronal diameters were determined from the axial images. The coronal images were used to measure the axial diameter (Figure 1). These measurements were employed to estimate the volume of reasonably regular shaped ellipsoid 
Original Article | PTBE to predict grade and resection of meningiomae

and concave objects by applying the formula $a b c / 2$, where $a$ is the sagittal diameter, $b$ is the coronal diameter and $c$ is the axial diameter (22-26). This formula was used to measure peritumoural brain Edema by employing high signal intensity changes on T2-weighted images
(Figure 2). The Edema index represents the degree of peritumoural Edema compared with tumour volume and is calculated by dividing the peritumoural brain Edema volume by the tumour volume. An Edema index of more than 1.0 signifies peritumoural brain Edema.

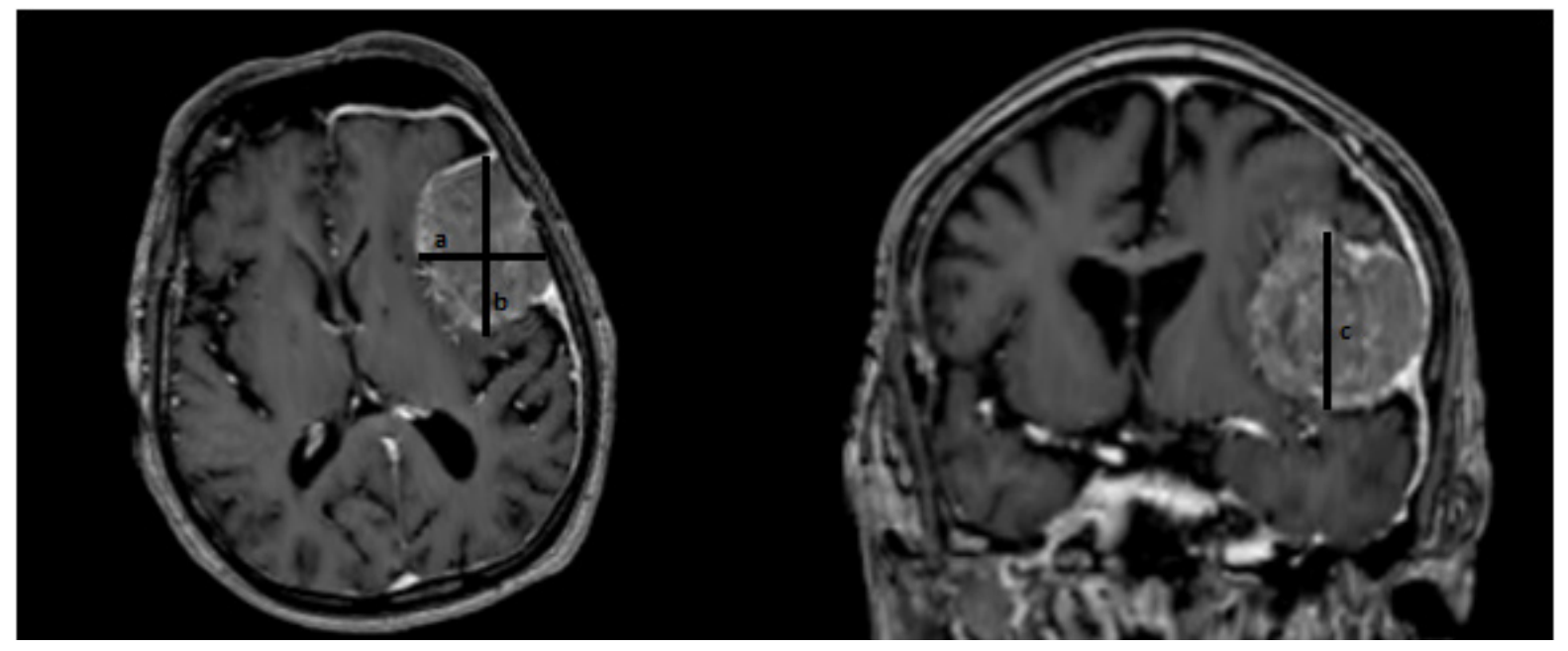

Figure 1. Illustration on how the diameters used in the calculation of tumour volume is measured

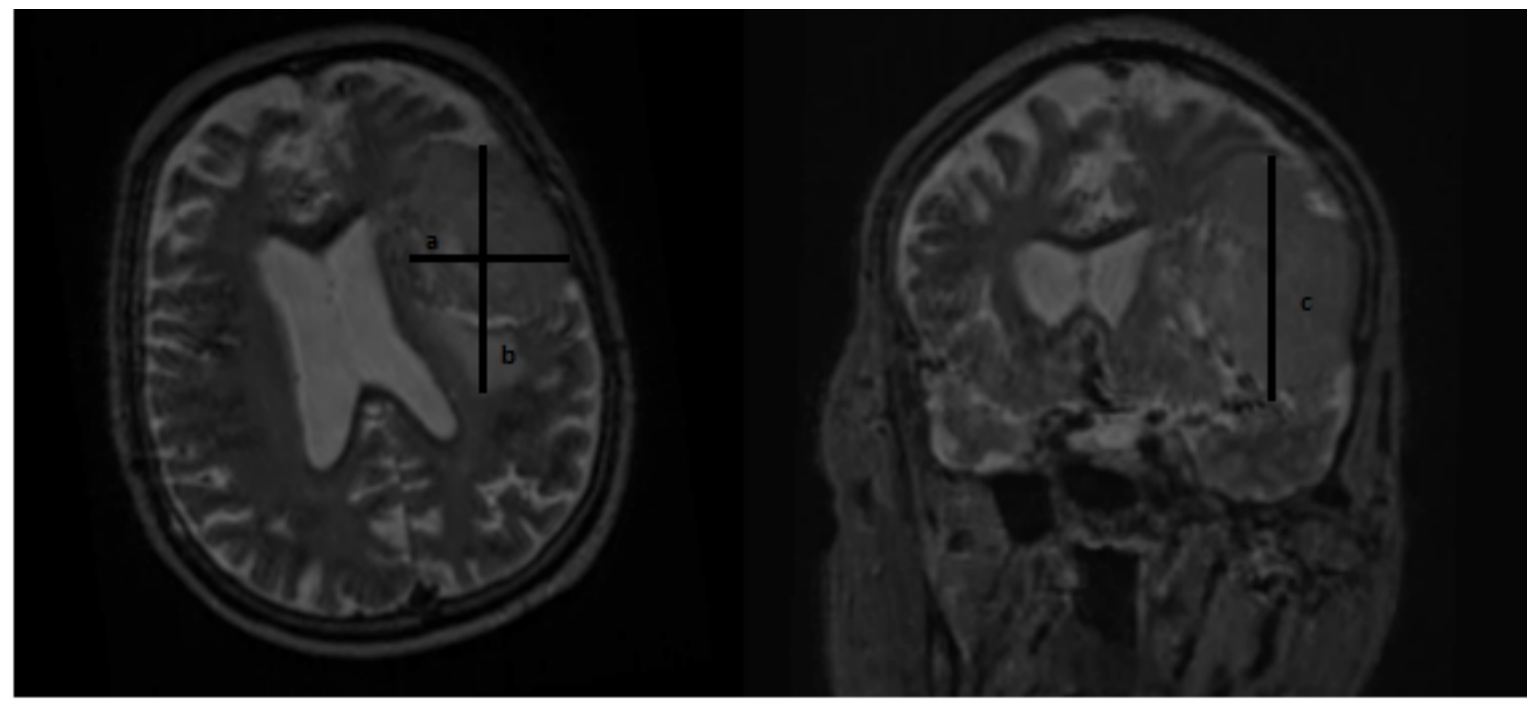

Figure 2. Illustration on how the diameters used in the calculation of peritumoural Edema volume is measured 


\section{Tumour grade}

The World Health Organisation (WHO) classifies meningioma using three distinct grades. Grade 1 denotes a low proliferative potential that may be cured through surgical resection. Grade 2 lesions are locally infiltrative with a tendency to recur, despite their low proliferative index. Grade 3 lesions generally show histological evidence of malignancy (3839). In terms of management, grades 2 and 3 require adjuvant therapy even after total tumour excision due to their tendency to recur and were thus classified as high grade in this study (42).

\section{Excision}

The extent of surgical resection of the meningioma has been reported to be correlated with recurrence and is distinguishable into five grades (16) (Table 1). To date, this is the most widely used and accepted grading system for meningioma resection. Generally, grades I-III denote complete macroscopic tumour excision.

Table 1. Summary Simpson Grading for excision of meningioma

\begin{tabular}{|c|c|}
\hline Grade & Description \\
\hline $\mathbf{1}$ & $\begin{array}{l}\text { Macroscopically complete removal of the tumour, with excision of its dural attachment, and } \\
\text { of any abnormal bone. Where the tumour arises from the wall of a dural venous sinus, such an } \\
\text { operation necessarily entails resection of the sinus. }\end{array}$ \\
\hline 2 & $\begin{array}{l}\text { Macroscopically complete removal of the tumour and of its visible extensions, with endothermy } \\
\text { coagulation (usually to the point of charring) of its dural attachment. }\end{array}$ \\
\hline 3 & $\begin{array}{l}\text { Macroscopically complete removal of the intradural tumour, without resection or coagulation } \\
\text { of its dural attachment, or alternatively, of its extradural extensions, e.g., an invaded sinus or } \\
\text { hyperostotic bone. }\end{array}$ \\
\hline 4 & Partial excision of tumour, leaving intradural tumour in situ. \\
\hline 5 & Simple decompression, with or without biopsy. \\
\hline
\end{tabular}

(Simpson, 1957)

\section{Residual tumour}

The presence of a residual tumour was determined by post-operative MRI, which is routinely performed between 12 and 24 weeks after surgery. The MRI images were interpreted by the resident neuroradiologist based on the contrast uptake and signal intensity changes.

\section{Surgeons' experience}

The surgeons were classified into three groups based on their number of years of experience after post-graduate training as follows: more than three years; between one and three years; and less than one year, which included the senior neurosurgery residents. This was a practical approach in our local setting because surgeons with less than one year of experience were still considered to be in training, while those with more than three years of experience were generally accepted as independent surgeons.

\section{Results}

During the study period, 168 confirmed intracranial meningioma cases were recorded. The histopathological records of the 168 cases revealed that 147 had grade 1 (low grade) meningioma and 21 showed grades 2 and 3 (high grade) meningioma, which implied an approximately $12.5 \%$ incidence of high-grade meningioma.

After analysing the demographic data, no significant association was found for age, gender or racial profile with the histological grading of meningioma. The $P$-value was greater than 0.05 in all cases (Tables 2 and 3 ).

Tumour volume and peritumoural brain Edema had a significant association with highgrade meningioma upon univariate statistical analysis. Multivariate analysis using binary logistic regression was performed on these independent variables (Table 4). Peritumoural brain Edema had an odds ratio (OR) of 6 with a 95\% confidence interval (CI) of $0.634-56.924$, whereas the tumour volume had an OR of 1.022 with a 95\% CI of 0.999-1.046 for the association 
Original Article | PTBE to predict grade and resection of meningiomae

with high-grade meningioma. The Nagelkerke R square was fairly representative at 0.439 .

Multivariate analysis of the independent variables, including the presence of peritumoural brain Edema, tumour volume, histological grading (grades 2/3) and surgeons' amount of experience compared with the presence of residual tumours on follow up reported as gross resection during surgery, was performed using binary logistic regression. The variables were found to be statistically insignificant (Table 5).

Table 2. Histological Outcome

\begin{tabular}{lccc} 
& \multicolumn{2}{c}{ Histopathology } & \multirow{2}{*}{ P-value } \\
\cline { 2 - 3 } Age & Low grade & High Grade & \\
Mean & & & \\
& 46.78 & 48.11 & $0.800^{\mathrm{a}}$ \\
Race & $\mathrm{SD}=15.46$ & $\mathrm{SD}=17.16$ & \\
Malay & & & \\
Chinese & $9(50.0)$ & $10(55.6)$ & \\
Indian & $6(33.3)$ & $6(33.3)$ & $0.496^{\mathrm{b}}$ \\
Others & $2(11.1)$ & 0 & \\
Gender & $2(5.6)$ & $2(11.1)$ & \\
Male & & & \\
Female & $3(16.7)$ & $5(27.8)$ & \\
Duration & $15(83.3)$ & $13(72.2)$ & \\
Mean (months) & 12.42 & 10.42 & \\
& $\mathrm{SD}=29.67$ & $\mathrm{SD}=84.10$ & \\
Seizures & & & \\
Absent & $14(77.8)$ & $10(55.6)$ & $0.164^{\mathrm{c}}$ \\
Present & $4(22.2)$ & $8(44.4)$ & \\
Tumour Volume & & & \\
Mean (cm 3 ) & 32.92 & 96.67 & $0.000^{\mathrm{b}}$ \\
& $\mathrm{SD}=29.67$ & $\mathrm{SD}=84.10$ & \\
Peritumoural Brain & & & \\
Oedema & $9(50.0)$ & $26(88.9)$ & \\
Absent & $9(50.0)$ & & \\
Present & & & \\
\hline
\end{tabular}

aMann-Whitney test applied

${ }^{\mathrm{b}}$ Chi-square test applied

${ }^{\mathrm{c}}$ Fisher exact test applied 
Table 3. Completeness of Resection

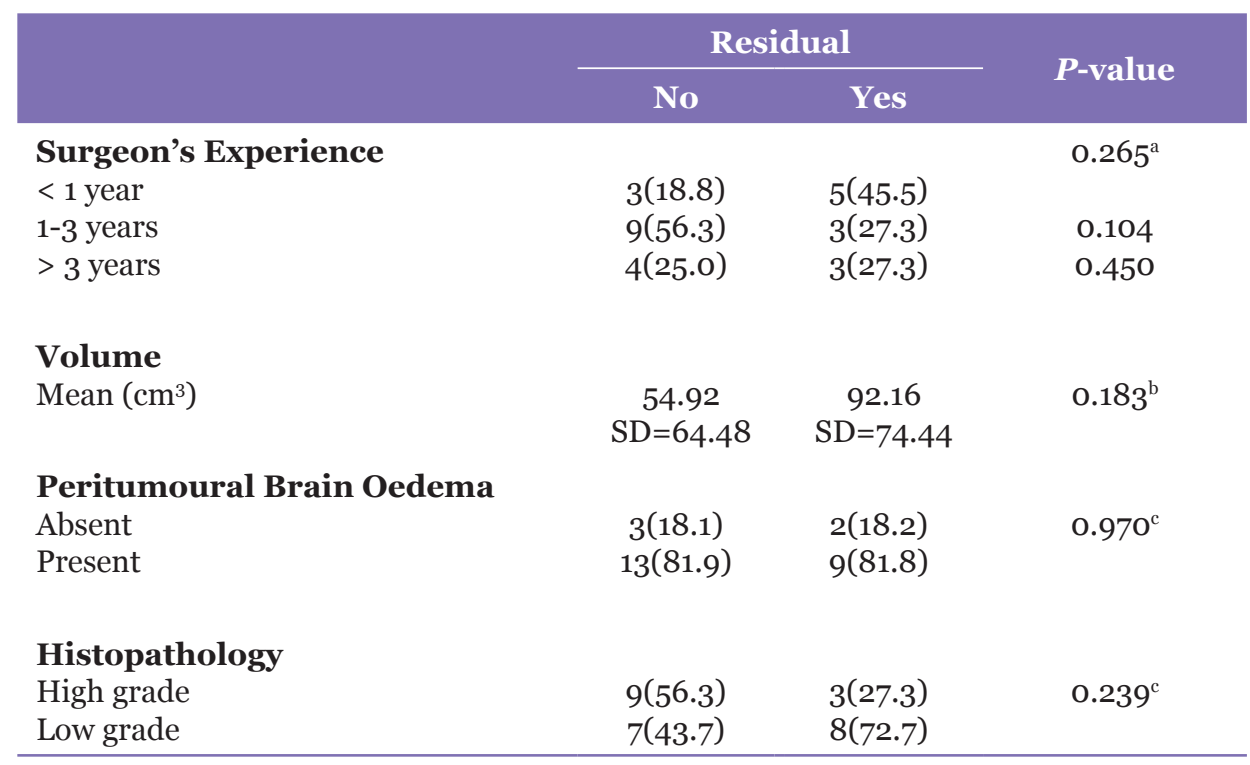

${ }^{\text {a} B i n a r y ~ l o g i s t i c ~ r e g r e s s i o n ~ a p p l i e d ~}$

${ }^{\mathrm{b}}$ Mann-Whitney test applied

cFisher exact test applied

Table 4. Factors which may affect the Histological Outcome

\begin{tabular}{lcccc} 
& Adjusted & \multicolumn{2}{c}{ 95\% CI } & P-value \\
& OR & Lower & Upper & \\
Tumour Volume & 1.022 & 0.999 & 1.046 & 0.061 \\
$\begin{array}{l}\text { Peritumoural Brain Oedema } \\
\begin{array}{l}\text { Oedema present } \\
\text { Oedema absent }\end{array}\end{array}$ & 6.006 & 0.634 & 56.924 & 0.118 \\
\hline
\end{tabular}

Table 5. Factors which may affect the Completeness of Resection

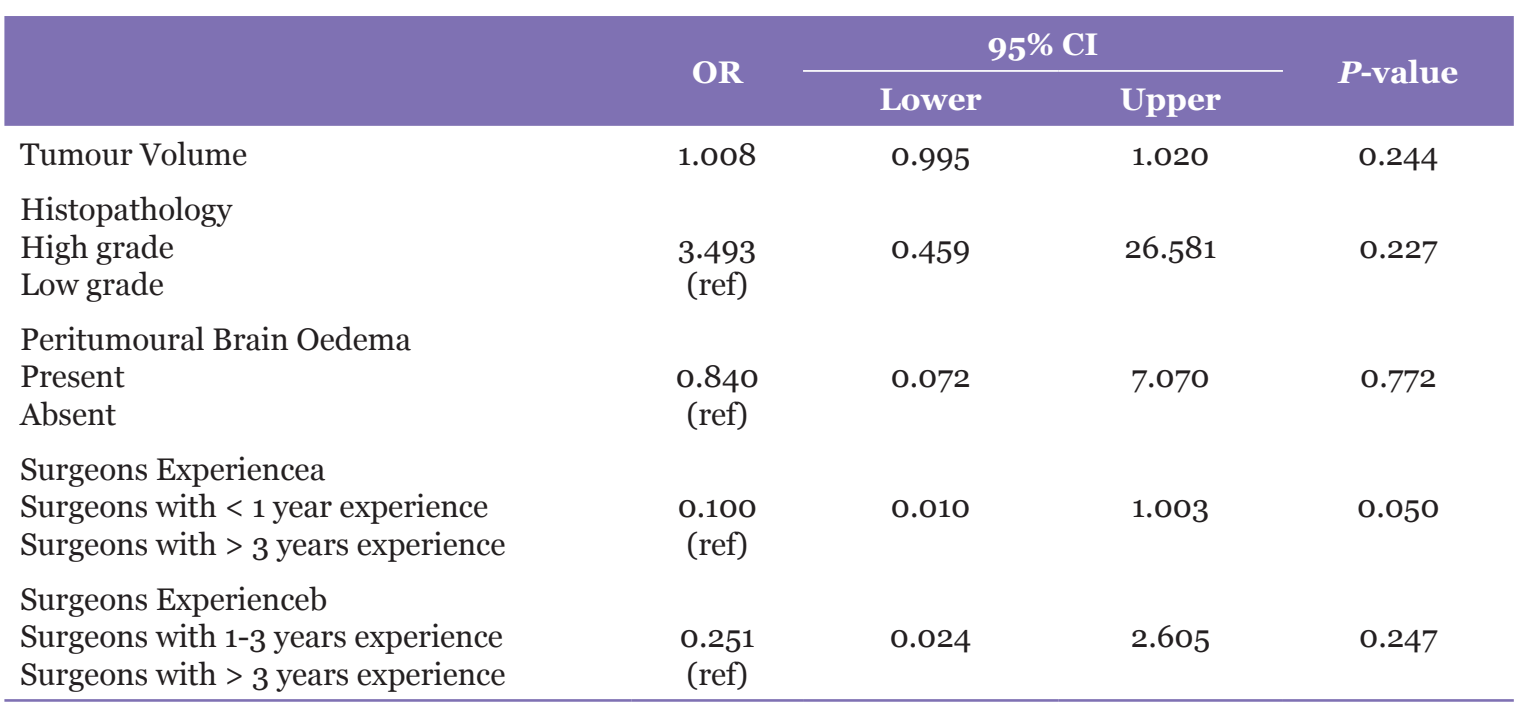

asurgeons with $<1$ year experience compared to surgeons with $>3$ years' experience

${ }^{\mathrm{b}}$ surgeons with 1-3 years' experience compared to surgeons with $>3$ years' experience 


\section{Discussion}

This study identified the incidence of highgrade meningioma to be $12.5 \%$. This finding concurs with the incidence of high-grade meningioma $(7.9 \%-35 \%)$ reported in other studies conducted after the introduction of the WHO 2000 classification scheme (27-29).

Grade 1 (low-grade) meningioma has a relatively good prognosis even with debulking; grades 2 and 3 (high-grade) meningiomas have a worse prognosis and necessitate adjuvant therapy (8-9). Physicians are often asked whether surgery is the end point of treatment or if adjuvant therapy will be required postoperatively. The ability to predict tumour grading will enable the physician to give a more accurate possibility of the treatment direction, instead of waiting for the formal and time-consuming histological diagnosis. Incomplete resection is linked to an increased need for vigilant surveillance necessitated by the residual tumour and also an increased likelihood for another surgery or adjuvant therapy.

Concurrent with the findings of other studies, the present study revealed women to be three times more likely to be diagnosed with meningioma than men. In contrast, men appeared to show a higher predisposition for high-grade meningioma (62.5\%) than women (46.4\%). Although this observation concurs with the indirect inference drawn by several other authors, it was statistically insignificant (31-32).

Ethnicity showed no predilection towards meningioma because the distribution based on racial composition almost mirrored the national racial composition, and this distribution pattern was observed in both the low- and high-grade tumour groups (30, 33).

Patients with a high-grade tumour reported a shorter duration of symptoms at presentation; however, this difference was statistically insignificant. To date, no studies have compared the growth rate of the different grades of meningioma. The differences in the clinical expansion rate between high- and lowgrade meningiomas were often not very distinct (34). Further studies are necessary to predict local tumour aggressiveness and possible timing of surgery to facilitate the safe allocation of resources.

Forty per cent of patients with high-grade meningioma had seizures at presentation, as compared with only $22 \%$ of patients with low-grade meningioma. The OR that a patient with high-grade meningioma would experience seizures was 2.8 and was statistically insignificant, which was in line with an earlier report (35). However, the incidence of seizures among patients included in the current study was much higher when compared with the findings of a similar and more recent study by Hamasaki et al. (31).

High-grade meningioma exhibited a threefold higher mean tumour volume than lowgrade meningioma $\left(96.67 \mathrm{~cm}^{3}\right.$ versus $32.92 \mathrm{~cm}^{3}$, respectively), which was statistically significant in the univariate analysis. However, the lack of earlier published data for a comparison of this finding warrants further investigation. The percentage of low-grade meningioma patients with peritumoural brain Edema was $50.0 \%$, while that of patients with high-grade meningioma and peritumoural brain Edema was $88.9 \%$. This finding was statistically significant upon univariate analysis, had an OR of 8 and concurs with the results reported in prior studies $(12,19,36)$, which suggested a positive correlation between peritumoural brain Edema and high-grade meningioma.

Among the 8 patients whose surgical procedure was performed by surgeons with less than 1 year of experience and were reported to have presented a gross total resection, 5 (62.5\%) had a residual tumour. However, this rate was the lowest at 25\% (3 out of 12 patients) among those patients who underwent surgery performed by surgeons with 1-3 years of experience. Nevertheless, the resection outcomes of the more senior surgeons ( $>3$ years of experience) were 3 out of $7(42.9 \%)$ cases, in whom gross total resection was noted and the residual tumour was identified on the follow-up MRI. This finding suggests that younger surgeons have a tendency to overestimate their successes, while the more senior surgeons might encounter more technically challenging tumours. Of the 7 cases performed by the senior surgeons, 3 were petroclival, 1 each involved the falx, medial third sphenoid wing and olfactory groove, and there was also 1 suprasellar tumour. In contrast, 7 out of the 8 cases handled by surgeons with less than one year's experience were convexity meningiomas. This theoretically will be easier to achieve complete resection.

The presence of peritumoural brain Edema does not significantly alter the morphology of the arachnoid plane or therefore impair the surgeons' judgement regarding the completeness of the resection. Among patients with residual brain tumours, follow-up MRIs indicated that $81.8 \%$ of them had peritumoural brain Edema, 
while $18.2 \%$ of patients did not. A similar observation was noted among those without residual tumours on follow-up MRIs (81.9\% revealed peritumoural brain Edema, while 18.1\% did not). In contrast, Vignes et al. reported a significant correlation between the presence of peritumoural brain Edema in meningioma and surgical difficulty during resection. They reported that $14(46.7 \%)$ patients had a clear arachnoid plane, while 16 (53.3\%) showed an ill-defined one. At the 1-year follow-up visit, mortality and nil recurrence were reported in 29 patients, while 8 patients had tumours present at the skull base (18).

High-grade tumours are linked to tumour infiltration into the adjacent tissue. Both grade 2 and grade 3 meningiomas have been reported to locally infiltrate (6). In fact, earlier studies have established a relationship between the presence of a high-grade tumour and its recurrence (37-39). However, in the literature review, no studies discussed the factors that produced inadvertent residual tumours in meningioma. We examined whether the histological grading influenced the totality of the resection and found that patients with high-grade meningioma had a 3.5-fold higher chance (OR: 3.49) of having a residual tumour, although this finding was not statistically significant.

Univariate analysis has indicated that the concurrent presence of peritumoural brain Edema and tumour volume has been associated with high-grade tumours (Table 4). Patients with peritumoural brain Edema were six times more likely to harbour a high-grade tumour when compared to those without it; this result was statistically significant, with a $P$-value of 0.118 . Similarly, a comparison of the tumour volumes revealed an OR of 1.022 with a $P$-value of 0.061 . This result could have significance because of the relatively small sample size, but it was not expected to reveal the relationship between the volume and tumour grade, which was beyond the scope of this work.

An earlier study reported significant difficulty in the surgical removal of the tumour in patients with peritumoural Edema preoperatively, which may have been due to arachnoid plane distortion (18). However, other studies have identified a positive association between the presence of peritumoural brain Edema and the recurrence of the meningioma, which could imply the presence of a residual tumour that might have been overlooked during the surgery $(40-41)$. Contrary to the aforementioned hypothesis, no statistically significant differences were identified in this study between the various factors examined and the completeness of tumour resection, as perceived by the surgeons (Table 5).

This study would have been of greater value and significance had the population under study had been categorised based on tumour location. It is widely accepted that the location of the tumour probably influences the tumour's respectability and perhaps also the presence of peritumoural brain Edema. However, such a categorisation will necessitate a much larger sample size, which in turn will increase the power of the study. A larger multicentre study is necessary, with one drawback of a multicentre study being the increased disparity of the surgeons' skills at each institution.

\section{Conclusion}

Initially, there appeared to be a connection between the higher grades of meningioma and peritumoural brain Edema, which was backed by univariate statistical analysis and also had a higher probability of advanced grades of meningioma with a rise in the tumour volume, a fact that has not been previously reported. However, the statistical significance of both the parameters decreased upon multivariate analysis, while the OR remained reasonably high $(\mathrm{OR}=6.0)$. It is evident that peritumoural brain Edema does not influence the intra-operative judgment of the surgeons on the entirety of the resection of a meningioma.

Although the factors studied generally had an insignificant effect upon the multivariate analysis, the influence of peritumoural brain Edema and tumour volume on the histological grading of meningioma cannot be disregarded. The scoring system for meningioma in the future must necessarily consider these two factors.

\section{Authors' Contributions}

Conception and design: KP, MSMH

Analysis and interpretation of the data: KP, NRMZ

Drafting of the article: KP

Critical revision of the article for important intellectual content: KP, MSMH, NRMZ

Final approval of the article: KP, MSMH

Provision of study materials or patients: KP, MSMH

Statistical expertise: KP

Obtaining of funding: KP 
Original Article | PTBE to predict grade and resection of meningiomae

Administrative, technical, or logistic support: KP Collection and assembly of data: KP, NRMZ

\section{Correspondence}

Dr Kamalanathan Palaniandy

MD (UKM), MS (NEUROSURGERY, USM)

Department of Surgery,

Faculty of Medicine, Universiti Kebangsaan Malaysia,

Hospital Canselor Tuanku Muhriz,

Pusat Perubatan UKM, 56000 Cheras,

Kuala Lumpur, Malaysia

Tel: +603 91456202

Fax: +603 91456684

E-mail: pkpknathan@hotmail.com

\section{References}

1. Claus EB, Calvocoressi L, Bondy ML, Schildkraut JM, Wiemels JL, Wrensch M. Family and persona medical history and risk of meningioma. $J$ Neurosurg. 2011;115(6):1072-1077. https://doi. org/10.3171/2011.6.JNS11129

2. Central Brain Tumor Registry of the United States. CBTRUS statistical report: Primary brain and central nervous system tumors diagnosed in the United States in 2004-2007. Hinsdale, IL: Central Brain Tumor Registry of the United States; 2011.

3. Mawrin C, Perry A. Pathological classification and molecular genetics of meningiomas. $J$ Neurooncol. 2010;99(3):379-391. https://doi. org/10.1007/s11060-010-0342-2

4. Cancer TIAfRo. WHO classification of tumours of the central nervous system. 4th ed. Lyon: International Agency for Research on Cancer (IARC); 2007.

5. Lieu AS, Howng SL. Intracranial meningiomas and epilepsy: incidence, prognosis and influencing factors. Epilepsy Res. 1999;38(1):45-52. https:// doi.org/10.1016/So920-1211(99)0oo66-2

6. Whittle IR, Smith C, Navoo P, Collie D. Meningiomas. Lancet. 2004;363(9420):15351543. https://doi.org/10.1016/So1406736(04)16153-9

7. Perry A, Scheithauer BW, Stafford SL, Lohse CM, Wollan PC. "Malignancy" in meningiomas: a clinicopathologic study of 116 patients, with grading implications. Cancer. 1999;85(9):20462056.
8. Marosi C, Hassler M, Roessler K, Reni M, Sant M, Mazza E, et al. Meningioma. Crit Rev Oncol Hematol. 2008;67(2):153-1571. https://doi. org/10.1016/j.critrevonc.2008.01.010

9. Milosevic MF, Frost PJ, Laperriere NJ, Wong CS, Simpson WJ. Radiotherapy for atypical or malignant intracranial meningioma. Int $J$ Radiat Oncol Biol Phys. 1996;34(4):817-822. https:// doi.org/10.1016/0360-3016(95)02166-3

10. Pronin IN, Holodny AI, Petraikin AV. MRI of high-grade glial tumors: correlation between the degree of contrast enhancement and the volume of surrounding edema. Neuroradiology. 1997;39(5):348-350. https://doi.org/10.1007/ s002340050421

11. Go GK, Wilmink JT, Molenaar WM. Peritumoral brain edema associated with meningiomas. Neurosurgery. 1988;23(2):175-179. https://doi. org/10.1227/00006123-198808000-00008

12. Tamiya $\mathrm{T}$, Ono $\mathrm{Y}$, Matsumoto $\mathrm{K}$, Ohmoto T. Peritumoral brain edema in intracranial meningiomas: effects of radiological and histological factors. Neurosurgery. 2001;49(5):1046-1051.

13. Lobato RD, Alday R, Gomez PA, Rivas JJ, Dominguez J, Cabrera A, et al. Brain Edema in patients with intracranial meningioma. Correlation between clinical, radiological, and histological factors and the presence and intensity of Edema. Acta Neurochir (Wien). 1996;138(5):485-493. https://doi.org/10.1007/ BFo1411166

14. Gilbert JJ, Paulseth JE, Coates RK, Malott D. Cerebral edema associated with meningiomas. Neurosurgery. 1983;12(6):599-605. https://doi. org/10.1227/00006123-198306000-00001

15. Gurkanlar D, Er U, Sanlı M, Özkan M, Sekerci Z. Peritumoral brain edema in intracranial meningiomas. J Clin Neurosci. 2005;12(7):750753. https://doi.org/10.1016/j.jocn.2004.09.029

16. Simpson D. The recurrence of intracranial meningiomas after surgical treatment. $J$ Neurol Neurosurg Psychiatry. 1957;20(1):22-39. https://doi.org/10.1136/jnnp.20.1.22

17. Harrigan MR. Angiogenic Factors in the central nervous system. Neurosurgery. 2003;53(3):639661. https://doi.org/10.1227/01.NEU.00000795 75.09923 .59 
18. Vignes JR, Sesay M, Rezajooi K, Gimbert E, Liguoro D. Peritumoral edema and prognosis in intracranial meningioma surgery. J Clin Neurosci. 2008;15(7):764-768. https://doi.org/10.1016/j. jocn.2007.06.001

19. Lee KJ, Joo WI, Rha HK, Park HK, Chough JK, Hong YK, et al. Peritumoral brain edema in meningiomas: correlations between magnetic resonance imaging, angiography, and pathology. Surg Neurol. 2008;69(4):350-355. https://doi. org/10.1016/j.surneu.2007.03.027

20. Kaal EC, Vecht CJ. The management of brain edema in brain tumors. Curr Opin Oncol. 2004;16(6):593-6oo. https://doi. org/10.1097/01.cco.0000142076.52721.b3

21. Simis A, Pires de Aguiar PH, Leite CC, Santana PA, Rosemberg S, Teixeira MJ. Peritumoral brain edema in benign meningiomas: correlation with clinical, radiologic, and surgical factors and possible role on recurrence. Surg Neurol. 2008;70(5):471-477. https://doi.org/10.1016/j. surneu.2008.03.006

22. Gebel JM, Sila CA, Sloan MA, Granger CB, Weisenberger JP, Green CL, et al. Comparison of the $\mathrm{ABC} / 2$ estimation technique to computerassisted volumetric analysis of intraparenchymal and subdural hematomas complicating the GUSTO-1 trial. Stroke. 1998;29(9):1799-1801. https://doi.org/10.1161/o1.STR.29.9.1799

23. Kothari RU, Brott T, Broderick JP, Barsan WG, Sauerbeck LR, Zuccarello M, et al. The ABCs of measuring intracerebral hemorrhage volumes. Stroke. 1996;27(8):1304-1305. https://doi. org/10.1161/01.STR.27.8.1304

24. Morgenstern L, Frankowski RF, Shedden P, Pasteur W, Grotta JC. Surgical treatment for intracerebral hemorrhage (STICH) A singlecenter, randomized clinical trial. Neurology. 1998;51(5):1359-1363. https://doi.org/10.1212/ WNL.51.5.1359

25. Huttner HB, Steiner T, Hartmann M, Köhrmann $\mathrm{M}$, Juettler E, Mueller S, et al. Comparison of $\mathrm{ABC} / 2$ estimation technique to computerassisted planimetric analysis in warfarinrelated intracerebral parenchymal hemorrhage. Stroke. 2006;37(2):404-408. https://doi. org/10.1161/o1.STR.ooo0198806.67472.5c
26. Zeidman LA, Ankenbrandt WJ, Du H, Paleologos $\mathrm{N}$, Vick NA. Growth rate of non-operated meningiomas. $J$ Neurol. 2008;255(6):891-895. https://doi.org/10.1007/s00415-008-0801-2

27. Sade B, Chahlavi A, Krishnaney A, Nagel S, Choi E, Lee JH. World Health Organization Grades II and III meningiomas are rare in the cranial base and spine. Neurosurgery. 2007;61(6):1194$1198 . \quad$ https://doi.org/10.1227/01. neu.0000306097.38141.65

28. Rogers L, Gilbert M, Vogelbaum MA. Intracranial meningiomas of atypical (WHO grade II) histology. J Neurooncol. 2010;99(3):393-405. https://doi.org/10.1007/s11060-010-0343-1

29. Willis J, Smith C, Ironside JW, Erridge S, Whittle IR, Everington D. The accuracy of meningioma grading: a 10-year retrospective audit. Neuropathol Appl Neurobiol. 2005;31(2):141149. https://doi.org/10.1111/j.13652990.2004.00621.x

30. Statistics Do. Population Distribution and Basic Demographic Characteristics Report. Population Housing Census. Putrajaya: Department of Statistics Malaysia Putrajaya; 2010.

31. Hamasaki T, Yamada K, Kuratsu J. Seizures as a presenting symptom in neurosurgical patients: A retrospective single-institution analysis. Clin Neurol Neurosurg. 2013;115(11):2336-2340. https://doi.org/10.1016/j.clineuro.2013.08.016

32. Hsu DW, Efird JT, Hedley-Whyte ET. Progesterone and estrogen receptors in meningiomas: prognostic considerations. $J$ Neurosurg. 1997;86(1):113-120. https://doi. org/10.3171/jns.1997.86.1.0113

33. Tan AC, Leong EW, Chua AC, Moy FM. Racial variations in booking haemoglobin of primigravidae in Malaysia: a prospective study. BMC res notes. 2013;6:173. https://doi. org/10.1186/1756-0500-6-173

34. Rubin G, Herscovici Z, Laviv Y, Jackson S, Rappaport ZH. Outcome of untreated meningiomas. Isr Med Assoc J. 2011;13(3):157160.

35. Chow SY, Hsi MS, Tang LM, Fong VH. Epilepsy and intracranial meningiomas. Zhonghua Yi Xue Za Zhi (Taipei). 1995;55(2):151-155. 
Original Article | PTBE to predict grade and resection of meningiomae

36. Smith HPMD, Challa VRMD, Moody DMMD, Kelly DLJMD. Biological features of meningiomas that determine the production of cerebral edema. Neurosurgery. 1981;8:428-433. https://doi. org/10.1227/00006123-198104000-00004

37. Jensen R, Lee J. Predicting outcomes of patients with intracranial meningiomas using molecular markers of hypoxia, vascularity, and proliferation. Neurosurgery. 2012;71(1):146-156. https://doi. org/10.1227/NEU.obo13e3182567886

38. Louis DN, Ohgaki H, Wiestler OD, Cavenee WK, Burger PC, Jouvet A, et al. The 2007 WHO classification of tumours of the central nervous system. Acta neuropathologica. 2007;114(2):97109. https://doi.org/10.1007/s00401-007-0243-4

39. Perry A, Louis DN, Scheithauer BW, Budka H, Deimling Av. WHO grading of tumours of the central nervous system. In: Louis DN, Ohgaki $\mathrm{H}$, Wiestler OD, Cavenee WK, editors. WHO classification of tumours of the central nervous system. Lyon: International Agency for Research on Cancer; 2007. p. 164-172.
40. Moussa WM. Predictive value of brain edema in preoperative computerized tomography scanning on the recurrence of meningioma. Alexandria Journal of Medicine. 2012;48:373-379. https:// doi.org/10.1016/j.ajme.2012.06.001

41. Mantle RE, Lach B, Delgado MR, Baeesa S, Belanger G. Predicting the probability of meningioma recurrence based on the quantity of peritumoral brain edema on computerized tomography scanning. $J$ Neurosurg. 1999;91(3):375-383. https://doi.org/10.3171/ jns.1999.91.3.0375

42. Walcott BP, Nahed BV, Brastianos PK, Loeffler JS. Radiation treatment for WHO grade II and III meningiomas. Frontiers in Oncology. 2013;3:227. https://doi.org/10.3389/fonc.2013.00227 